\title{
Improving Energy Efficiency by Advanced Traffic Control Systems
}

\author{
Miroslav Vujića, Ivana Šemanjski ${ }^{\mathrm{b}}$, Pero Vidan
}

The problem of traffic congestion is particularly acute in urban areas in which the possibilities for the physical increase of capacities are limited or nonexistent. Traffic congestion has a direct impact on the emission, energy efficiency and fuel consumption of personal vehicles. Several projects in the European Union are focused on solving this problem (both at the physical level - automotive industry, as well as at the traffic management level). This paper explores the possibility of the implementation of advanced traffic control systems in urban areas in which driving behavior involves a multitude of stopand-go actions, lower speeds in lower vehicle gears. Since this type of driving behavior affects vehicle fuel consumption and emission, relevant evaluation parameters were defined (queue length, average vehicle speed, etc.). A demonstration corridor in the city of Zagreb was chosen and a simulation model based on the traffic data collected in real traffic situations developed. The basis for further research is laid down to allow the application of the proposed model and adaptive traffic control algorithms to the greater urban traffic network.

\section{KEY WORDS}

$\sim$ Intelligent Transport Systems

$\sim$ Fuel Consumption

$\sim \mathrm{CO}_{2}$ Emission

$\sim$ Signal Control

a. Faculty of Transport and Traffic Sciences, University of Zagreb, Zagreb, Croatia e-mail: miroslav.vujic@fpz.hr

b. Department of Telecommunications and Information Processing, Gent University, Gent, Belgium

e-mail: ivana.semanjski@telin.ugent.be

c. University of Split, Faculty of Maritime Studies, Split, Croatia

e-mail: pero.vidan@pfst.hr

\section{INTRODUCTION}

Nowadays, traffic and transportation are the sector with the highest energy consumption, especially in urban areas where driving regimes (greater number of stop-and-go actions, lower average speeds, etc.) differ from "normal", free ride driving regime (International Energy Agency, 2009). Apart from efforts to reduce emissions at the physical level (Kadijk et al., 2015), signal control logic could also be regulated across a wider area to allow the reduction of a part of vehicle energy efficiency parameters. Likewise, raising the quality of public transportation (PT) systems may lead to the reduction of the number of personal vehicles in urban areas (Vujic, 2013). Global industrial demand for primary energy is projected to rise by $40 \%$ by 2030 in comparison with the 2007 levels. This would put global energy-related $\mathrm{CO}_{2}$ emissions at 40.2 gigatonnes (Gt) in 2030, with an annual growth rate of 1.5 \% (International Energy Agency, 2009). The International Energy Agency (IEA) estimates that there is a potential for a $50 \%$ technical improvement in new vehicle fuel economy by 2030 (International Energy Agency, 2009a; Gudelj and Krčum, 2013). The usage of PTV VISSIM simulation tool for modelling energy efficiency and fuel consumption started in the first decade of the 21st century (Stathopoulos and Noland, 2003; Scora and Barth, 2006). But in the quoted papers, the optimization of relevant parameters was not considered. The optimization of signal timings at signalized intersections in urban areas reduces the waiting time of vehicles, while simultaneously having a direct impact on the energy efficiency of personal vehicles (Shamshirband, 2012). Owing to the increasing consciousness of traffic and transport pollutants, several European Union (EU) funded Framework Program 7 (FP7) projects aim to deal with this issue. One of them is the eCoMove Integrated Project aiming to reduce the overall fuel consumption by $20 \%$ with the usage of several advanced intelligent transport system (ITS) solutions (eCoMove, 2013). 


\section{PUBLIC TRANSPORTATION PRIORITY STRATEGIES}

The delays of public transportation vehicles at signalized intersections account for $27 \%$ - $35 \%$ of all delays induced by all traffic in the urban network (including public transportation) (Zhizhou et al., 2014). Advanced adaptive control of signalized intersections includes turning on green lights for public transport vehicles whenever possible. Three main approaches in PTP assignments are defined as ( Nash and Sylvia, 2001):

- passive approach,

- unconditional approach,

- $\quad$ active approach.

Predefined signal schemes are used when implementing passive priority approach to contribute to the reduction of public transportation vehicle travel times. The passive priority approach does not require the presence of a public transportation vehicle, nor a notification of its arrival to a signalized intersection. Specific passive priority techniques include cycle length reduction and phase splitting.

Public transportation vehicles are given unconditional priority at signalized intersections regardless of which phase of the cycle is active. After the end of the active phase (taking into consideration minimum safety/passenger green times), green light for public transportation vehicles is immediately activated. Although rarely used in public transportation, the unconditional approach is widely used for emergency and VIP vehicle priority assignment.

Active priority techniques are activated only when a public transportation vehicle arrives at a signalized intersection, or when a priority demand is sent to the control center. After the demand is sent, the priority technique is activated within the limits of minimum safety parameters.

Active approach techniques include green light phase extension, early green light phase (red light truncation), green light phase insertion, phase rotation or substitution and selective strategies.

\section{a) Green phase extension}

If public transportation vehicle approaches a signalized intersection, and green light is on, it can be extended for a period required by a public transportation vehicle to pass through the

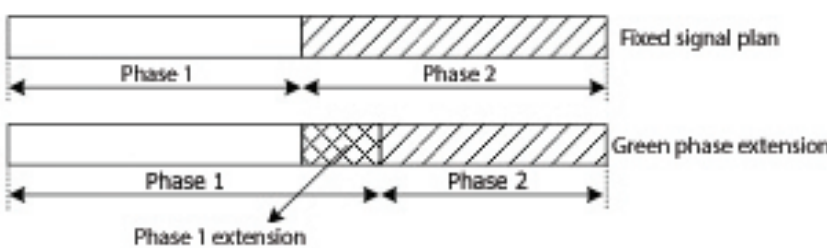

Figure 1.

Green phase extension technique. intersection (Figure 1). Maximum extension limit is used to limit the impact on cross street vehicles.

Different projects and references define maximum green light extension times ranging from 10-20s in the implemented scenarios (Hounsell and Shretsha, 2012).

b) Early green phase (red light truncation)

If public transportation vehicle approaches a signalized intersection, and red light is active, it can be shortened so that early green phase can be activated (Figure 2 ).

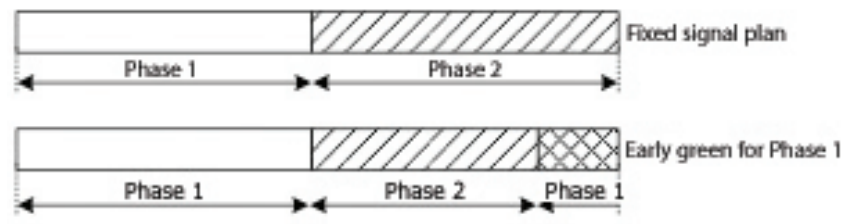

Figure 2.

Early green light phase (red light truncation) technique.

Maximum red light truncation values are lower than green light extension values because red light truncation depends on the inter-green light matrix (minimum time necessary for pedestrians to cross the road).

c) Green light phase insertion

If a public transportation vehicle approaches a signalized intersection (with three or more signal phases) green light (which is not in the signal expected in the cycle) may be introduced to accommodate the approaching public transportation vehicle (Figure 3).

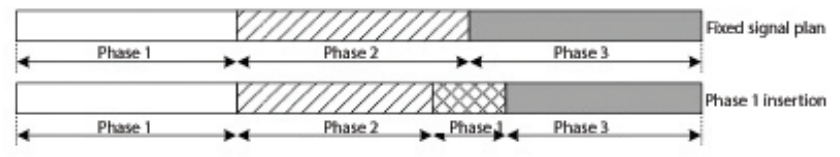

Figure 3.

Green light phase insertion technique.

A certain phase of the signal cycle can be skipped when there is no traffic load in the respective lane. In that case, green light for an approaching public transportation vehicle may be turned on, thus reducing the public transportation vehicle delay (Vujic, 2015). After PT vehicle detection, the system calculates the anticipated time of vehicle arrival at the signalized intersection.

\section{USE CASE - DEMONSTRATION CORRIDOR IN THE CITY OF ZAGREB}

One of the main traffic problems in the City of Zagreb is the daily commutation of inhabitants from one part of the City to another 
(mostly east-west and vice versa). The traffic corridor of King Zvonimir Street is one of the main links connecting the east part of the City with the City center (Figure 4). The corridor is 2,690 $\mathrm{m}$ long, with traffic in both directions, with separated public transportation (PT) lanes.

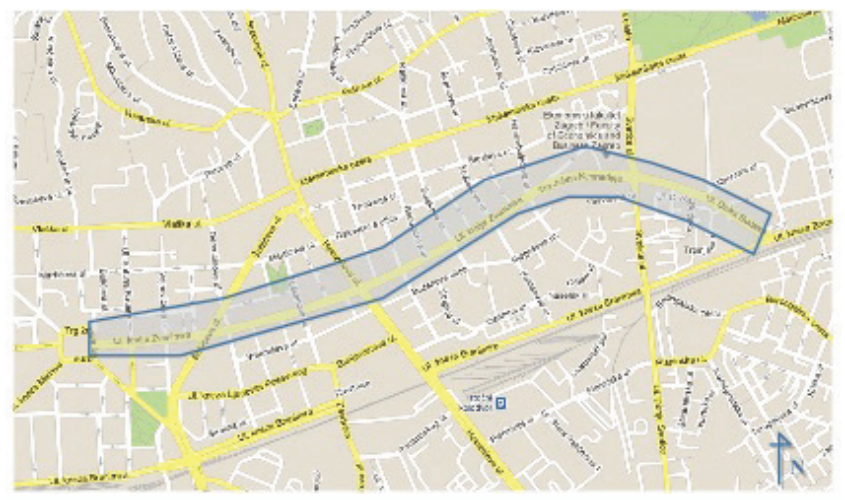

Figure 4.

Selected demonstration corridor in the city of Zagreb.

There are 24 intersections in the corridor, eight of which are signalized. All intersections have horizontal and vertical traffic signalization, and signalized intersections are also equipped with signal controllers using fixed control logic.

The simulation model was defined and developed in the PTV VISSIM simulation software in keeping with the collected reallife data (number of vehicles and their categorization). The morning rush hour was selected (8 AM - $9 \mathrm{AM}$ ), and relevant data were implemented into the simulation model. Owing to the complexity of the simulation model and a vast amount of traffic data, only one intersection was selected for this research (Figure 5) for data collection and evaluation.

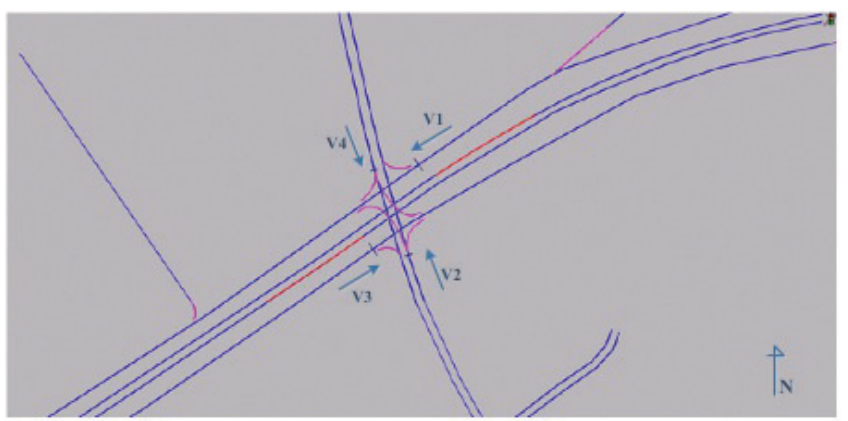

Figure 5.

Signalized intersection Harambašićeva Street - King Zvonimir Street.
The main traffic flow is the King Zvonimir Street (signal groups V1 and V3), with two lanes in each direction (eastbound and westbound), with the side lane being Harambasiceva Street (signal groups V2 and V4), with one lane in each direction. The fixed signal program is illustrated in Figure 6 with a signal cycle duration of $90 \mathrm{~s}$.

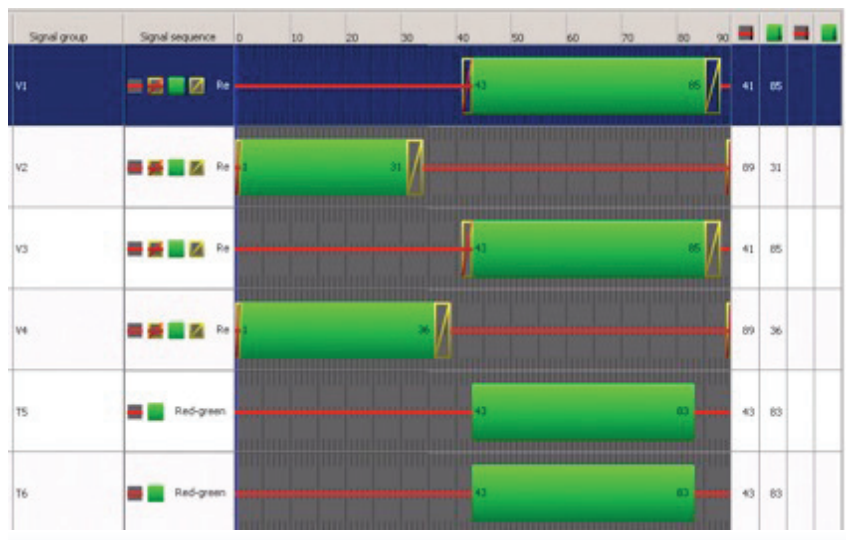

Figure 6.

Fixed signal program for the selected signalized intersection.

The fixed signal program clearly shows the control to be a twophase signal plan with four signal groups for road traffic (V1, V2, V3 and V4) and two signal groups for public transportation vehicles (T5 and T6).

\subsection{Adaptive Traffic Control of the Signalized Intersection}

Although the proposed scenario includes adaptive traffic control of all signalized intersections in the selected corridor, a detailed description and data collection/evaluation are presented for only one intersection (Harambasiceva Street - King Zvonimir Street). Detector D2 is positioned at the northern approach to the intersection at the distance of $30 \mathrm{~m}$ from the stop line, since the average queue length is 8 vehicles. Respectively, detector D3 (at the eastern approach) is positioned $20 \mathrm{~m}$ from the stop line, since the average queue length is 4 vehicles.

If there are no road vehicles (or their number is smaller than the average queue length number) on the side lane detectors (D2 and/or D3), the main flow phase of $10 \mathrm{~s}$ is extended to $50 \mathrm{~s}$. In case that a road vehicle activates D2 and/or D3 detectors (after $40 \mathrm{~s}$ of the main flow phase), side lane phase is activated for $20 \mathrm{~s}$ (which is $10 \mathrm{~s}$ shorter than in the fixed signal program).

Since the number of vehicles in the main flow is greater than the number of vehicles in the side lane approaches, and PT vehicles are part of the main flow, this algorithm can increase the level of service (LoS) at all signalized intersections in the selected 
corridor. After the completion of the side lane phase (duration of $20 \mathrm{~s}$ ), the main flow phase is activated, and the presence of vehicles on side lane detectors reexamined.

\section{SIMULATION RESULTS}

The first stage of simulation model development consists of making traffic network sketches (road and PT lanes, signalized intersections, etc.), defining signal plans, establishing the location of signal lanterns at every signalized intersection, entry of vehicle numbers and classification data, connecting signal logic with adaptive traffic control algorithms, etc. (PTV AG, 2014).

\subsection{Simulation Model of the Selected Corridor}

Following the calibration of the simulation model against the actual situation in the selected corridor, evaluation parameters pertaining to energy efficiency and emissions (Molina, 2005) needed to be defined. Based on the available data, vehicle compositions were entered into the simulation model, and the

Table 1.

Estimated classification of personal vehicles used in the simulation model.

\begin{tabular}{lll}
$\begin{array}{l}\text { EURO engine } \\
\text { category }\end{array}$ & $\begin{array}{l}\text { Petrol engine } \\
\text { vehicles }\end{array}$ & $\begin{array}{l}\text { Diesel engine } \\
\text { vehicles }\end{array}$ \\
\hline EURO II & $15 \%$ & $10 \%$ \\
\hline EURO III & $30 \%$ & $20 \%$ \\
\hline EURO IV & $15 \%$ & $10 \%$ \\
\hline
\end{tabular}

simulation was ran exclusively for personal vehicles with petrol and diesel engines (Table 1).

Evaluation parameters are defined and described in the following chapters.

\subsection{Link Evaluation}

Since results can be collected and evaluated at link level, four links were defined (Figure 7).

At the link level, following evaluation parameters were defined:

- average vehicle speed $[\mathrm{km} / \mathrm{h}]$,

- traffic flow [veh/km],

- $\mathrm{CO}_{2}$ emission $[\mathrm{mg} / \mathrm{m}]$,

- fuel consumption $[\mathrm{mg} / \mathrm{m}]$.

Simulation duration was 3600 s (defined rush hour), with additional $1800 \mathrm{~s}$ for network charging, and the defined data collection interval was $60 \mathrm{~s}$. Gathered results are shown in Table 2 and Table 3.

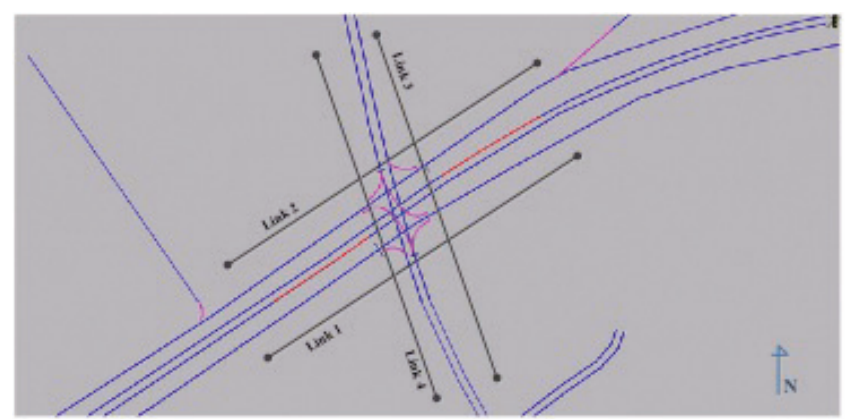

Figure 7.

Definition of links at the selected intersection.

Table 2.

Gathered results for the existing traffic situation.

\begin{tabular}{lllll} 
Link & Average speed $[\mathbf{k m} / \mathbf{h}]$ & Traffic flow [veh/h] & $\mathbf{C O}_{\mathbf{2}}$ emission $[\mathbf{m g} / \mathbf{m} / \mathbf{s}]$ & $\begin{array}{l}\text { Fuel consumption } \\
\text { [mg/m/s] }\end{array}$ \\
\hline Link 3 & 33.60776279 & 239.3355774 & 12.34101689 & 3.920178699 \\
\hline Link 4 & 25.26322023 & 223.9535919 & 14.11279782 & 4.484941204 \\
\hline Link 2 & 28.345801 & 594.3164542 & 31.91026888 & 10.12928811 \\
\hline Link 1 & 20.77310873 & 789.115241 & 54.51243549 & 17.30349592 \\
\hline
\end{tabular}


Table 3.

Gathered results for the simulation with implemented adaptive traffic control.

\begin{tabular}{lllll} 
Link & Average speed $[\mathbf{k m} / \mathbf{h}]$ & Traffic flow $[\mathbf{v e h} / \mathbf{h}]$ & $\mathbf{C O}_{\mathbf{2}}$ emission $[\mathbf{m g} / \mathbf{m} / \mathbf{s}]$ & $\begin{array}{l}\text { Fuel consumption } \\
{[\mathbf{m g} / \mathbf{m} / \mathbf{s}]}\end{array}$ \\
\hline Link 3 & 29.95277839 & 240.9064021 & 12.81411279 & 4.068477747 \\
\hline Link 4 & 21.65459486 & 222.7703678 & 15.52181427 & 4.931558853 \\
\hline Link 2 & 32.748382 & 604.3792071 & 31.11571712 & 9.876467152 \\
\hline Link 1 & 29.57466041 & 786.5396428 & 43.72176149 & 13.87812517 \\
\hline
\end{tabular}

Tables 2 and 3 clearly show that all defined parameters are improved with the same traffic flow at all approaches to the selected intersection. However, significant improvement is realized at main flow approaches because adaptive traffic control is defined in favor of the main traffic flow (greater number of vehicles).

\subsection{Time Loss - Queue Length}

A parameter directly illustrating the impact of adaptive traffic control on traffic flow is queue length. In PTV VISSIM, a vehicle is considered to be in queue when its speed drops under $3 \mathrm{~km} / \mathrm{h}$, maximum $100 \mathrm{~m}$ from the stop line to the last vehicle under the same conditions, until its speed exceeds $5 \mathrm{~km} / \mathrm{h}$. Queue counters detecting vehicles upstream are positioned on stop lines. In the selected demonstration corridor, four queue counters were defined as seen in Figure 8.

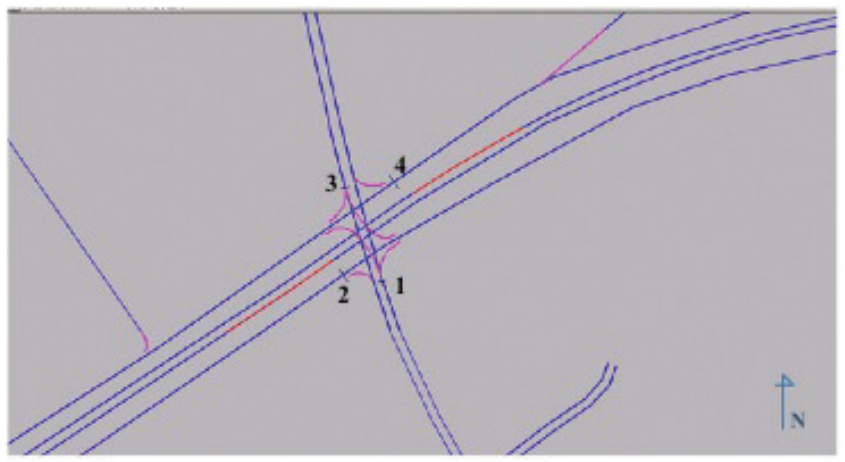

Figure 8.

Queue counter placement in the simulation model.
Data are gathered every five minutes and shown in Tables 4 and 5.

Table 4.

Queue length and number of stops in the existing situation.

\begin{tabular}{|llll} 
Counter & $\begin{array}{l}\text { Average } \\
\text { queue } \\
\text { length [veh] }\end{array}$ & $\begin{array}{l}\text { Maximum } \\
\text { queue } \\
\text { length [veh] }\end{array}$ & $\begin{array}{l}\text { Number of } \\
\text { stops }\end{array}$ \\
\hline 1 & 3.16 & 38 & 7.5 \\
\hline 2 & 6.58 & 52 & 2.54 \\
\hline 3 & 7.8 & 51 & 13 \\
\hline 4 & 16.08 & 77 & 53.16 \\
\hline
\end{tabular}

Table 5.

Queue length and number of stops for the simulation model with implemented adaptive traffic control.

\begin{tabular}{|llll} 
Counter & $\begin{array}{l}\text { Average } \\
\text { queue } \\
\text { length [veh] }\end{array}$ & $\begin{array}{l}\text { Maximum } \\
\text { queue } \\
\text { length [veh] }\end{array}$ & $\begin{array}{l}\text { Number of } \\
\text { stops }\end{array}$ \\
\hline 1 & 4.33 & 45 & 9.58 \\
\hline 2 & 4.33 & 52 & 21.75 \\
\hline 3 & 9.58 & 50 & 12.6 \\
\hline 4 & 6.75 & 68 & 27.16 \\
\hline
\end{tabular}

As shown in Tables 4 and 5 and Figure 8, counters are positioned on the stop lines of every approach to the selected intersection. Counter 1 is located at the southern approach, counter 2 at the western approach, etc. The number of stops is a parameter describing the average number of situations in which road vehicle 
speed is $0 \mathrm{~km} / \mathrm{h}$, which is cumulated for every vehicle upstream of the stop line. At the southern approach (counter 1), the average number of stops is slightly higher due to the shorter duration of the green light at this approach (according to the implemented adaptive control algorithm). As expected, the average number of stops at main line approaches decreased (especially at the eastern approach) owing to the longer duration of green lights.

\subsection{PT Vehicle Time Savings - Average Public Transportation Travel Time}

Apart from the defined parameters, another important indicator of adaptive traffic control efficiency is average PT travel time (measured along the entire demonstration corridor). Two 2,500 $\mathrm{m}$ long travel time sections were defined in the simulation model (one in each direction). The measured PT travel times are shown in Tables 6 and 7.

Table 6.

Measured PT travel times for the existing traffic simulation.

\begin{tabular}{llllll} 
Direction & $\begin{array}{l}\text { Average PT travel } \\
\text { time [s] }\end{array}$ & $\begin{array}{l}\text { Standard } \\
\text { deviation [s] }\end{array}$ & Minimum [s] & Maximum [s] & $\begin{array}{l}\text { Average PT speed } \\
{[\mathbf{k m} / \mathbf{h}]}\end{array}$ \\
\hline Westbound & 671.1 & 57 & 544.1 & 803.9 & 13.4 \\
\hline Eastbound & 696.8 & 71 & 475.3 & 891.8 & 12.9 \\
\hline
\end{tabular}

Table 7.

Measured PT travel times for the simulation model with implemented adaptive traffic control.

\begin{tabular}{llllll} 
Direction & Average PT travel & $\begin{array}{l}\text { Standard } \\
\text { time [s] }\end{array}$ & Minimum [s] & Maximum [s] & $\begin{array}{l}\text { Average PT speed } \\
\text { [km/h] }\end{array}$ \\
\hline Westbound & 631.6 & 48.2 & 533.7 & 715.8 & 14.2 \\
\hline Eastbound & 654.3 & 57.6 & 557 & 795.5 & 13.8 \\
\hline
\end{tabular}

The main evaluation parameter in the defined travel time sections was average PT travel time. Owing to the specifics of the developed adaptive traffic control (favoring main traffic flow used by PT vehicles), average travel time was decreased by 39.5 $\mathrm{s}$ in the westbound direction and by $42.5 \mathrm{~s}$ in the eastbound direction. Respectively, as average PT travel time decreased, average PT vehicle speed increased. This only applies if the number of passengers remains the same. Of course, if the quality of PT service improves, the number of passengers is expected to increase. In that case, the relations between these parameters would change.

\section{RESULT ANALYSIS}

In the previous chapter the simulation model development process was presented, as were the results realized in the existing traffic situation and using the adaptive traffic control model. Since the main traffic flow (King Zvonimir Street) is simultaneously a PT line route, the benefits of adaptive traffic control are obvious. Link level evaluation was conducted for the entire demonstration corridor, with adaptive traffic control algorithms implemented at all signalized intersections. Other gathered data were evaluated for only one selected signalized intersection, but projections were made for the entire corridor taking into consideration distances traveled under different driving regimes.

\subsection{Link Level Evaluation}

At link level, evaluated defined parameters were the average speed of personal vehicles, traffic flow (for each defined link), $\mathrm{CO}_{2}$ emission and fuel consumption. As expected, the average speed of personal vehicles in main (priority) lanes increased, while decreasing in the side lanes. This is mainly due to the shortening of green light duration (signal phase) in the side lanes, with unmodified duration of the signal cycle.

In the main lane (eastbound direction), the average personal vehicle speed increased from $29.07 \mathrm{~km} / \mathrm{h}$ to $33.01 \mathrm{~km} / \mathrm{h}$ (an increase of $3.94 \mathrm{~km} / \mathrm{h}$ ), and in the westbound direction from 22.81 $\mathrm{km} / \mathrm{h}$ to $26.90 \mathrm{~km} / \mathrm{h}$ (an increase of $4.09 \mathrm{~km} / \mathrm{h}$ ). In the side lane (southbound direction), average speed decreased from 36.57 $\mathrm{km} / \mathrm{h}$ to $35.53 \mathrm{~km} / \mathrm{h}$, and in the opposite direction (northbound) from $28.11 \mathrm{~km} / \mathrm{h}$ to $27.17 \mathrm{~km} / \mathrm{h}$, which is not a drastic decrease of average speed. 
$\mathrm{CO}_{2}$ emission and fuel consumption are also important evaluation parameters in link level evaluation, but since they depend on queue lengths (stop-and-go actions) at every intersection approach, queue length will be analyzed in the next section.

\subsection{Queue Length and Average Number of Stops}

Queue length and average number of stops were measured in the simulation for every approach to the intersection. In the main traffic flow (with implemented adaptive traffic control), the values of the above parameters decreased when compared to the existing traffic situation with fixed signal timings. At the western approach (Counter 2), average queue length decreased from 6.58 to 5 vehicles, with the average number of stops decreasing from
24.33 to 20.33 stops. At the eastern approach, average queue length decreased from 16.08 to 11.25 vehicles, with the average number of stops decreasing from 53.16 to 37.41 stops. These data show that queue length decreased along the entire main traffic flow (King Zvonimir Street), having a direct impact on fuel consumption and emission.

\section{3. $\mathrm{CO}_{2}$ Emission and Fuel Consumption}

Based on the collected data, implemented adaptive traffic control algorithms were anticipated to reduce $\mathrm{CO}_{2}$ emission and fuel consumption. Table 8 shows the total values of $\mathrm{CO}_{2}$ emission and fuel consumption for one hour (rush hour) of the simulation, for all vehicles passing through the chosen intersection.

Table 8.

Total values of $\mathrm{CO}_{2}$ emission and fuel consumption for the selected intersection.

\begin{tabular}{lllll} 
& Existing situation & & \multicolumn{2}{c}{ Adaptive traffic control } \\
\hline Link/lane & CO $_{2}$ emission $[\mathbf{m g} / \mathbf{m} / \mathbf{s}]$ & $\begin{array}{l}\text { Fuel consumption } \\
{[\mathbf{m g} / \mathbf{m} / \mathbf{s}]}\end{array}$ & $\mathbf{C O}_{\mathbf{2}}$ emission $[\mathbf{m g} / \mathbf{m} / \mathbf{s}]$ & $\begin{array}{l}\text { Fuel consumption } \\
{[\mathbf{m g} / \mathbf{m} / \mathbf{s}]}\end{array}$ \\
\hline Northbound & 2953.644 & 48.378 & 3087.001 & 52.133 \\
\hline Southbound & 3160.611 & 63.295 & 3457.800 & 76.546 \\
\hline Eastbound & 18964.797 & 323.228 & 18805.692 & 307.313 \\
\hline Westbound & 43016.593 & 943.255 & 34388.898 & 606.776 \\
\hline TOTAL & 68095.647 & 1378.158 & 59739.393 & 1042.770
\end{tabular}

The analysis of results from Table 8 shows that the total $\mathrm{CO}_{2}$ emission of vehicles passing through the chosen intersection in one hour decreased by $12.3 \%$ when compared to the existing situation. The gathered fuel consumption values are $24.36 \%$ lower in the simulation model with implemented adaptive traffic control algorithms.

\section{CONCLUSION}

In urban areas, adaptive traffic control is not only an essential tool for traffic flow harmonization, but also a very effective tool for improving energy efficiency and reducing emissions and fuel consumption. This research focused on the introduction of adaptive traffic control into a 2,690 m long demonstration corridor in the City of Zagreb. Based on the results achieved and the analysis of a signalized intersection in the selected corridor (Harambasiceva Street - King Zvonimir Street), vehicles at any intersection can be concluded to enter into a different driving mode (repetition of stop-and-go actions, waiting to pass the intersection, etc.). The estimated length of this type of driving in the selected corridor is 2,000 m, i.e. approx. $2 / 3$ of the corridor, with the "free ride" regime in the remainder of the corridor being unsuitable for improving on the defined parameters (average speed, $\mathrm{CO}_{2}$ emission, fuel consumption, etc.) by introducing adaptive traffic control strategies. At the level of the entire corridor, an overall reduction of $\mathrm{CO}_{2}$ by $5.5 \%$, and fuel consumption by $14.8 \%$ can be expected based on the analysis and the defined areas of traffic light intersections. The introduction of an adaptive management area larger city network to increase the average speed of road vehicles, reduce $\mathrm{CO}_{2}$ emissions and fuel consumption is possible. Further research will focus on the expansion of the corridor in a part of the City of Zagreb, and on gathering additional data from vehicles to improve the accuracy of simulation results. The improved public transportation system is expected to attract greater numbers of PT users, consequently reducing the number of personal vehicles.

\section{REFERENCES}

eCoMove, (2013), Cooperative Mobility Systems and Services for Energy Efficiency, Development and Testing of Traffic Management And Control Measures, D.5.7., available at:

http://www.transport-research.info/Upload/

Documents/201212/20121211_105904_61055_D5.7_-_Development_and_

Testing_of_Traffic_Management_and_Control_Measures.pdf 
Gudelj, A. and Krčum, M., (2013), Simulation and Optimization of Independent Renewable Energy Hybrid System, Transactions on Maritime Science, 2(1), pp. 28-35. http://dx.doi.org/10.7225/toms.v02.n01.004

Hounsell, N. and Shretsha, B., (2012), A New Approach for Cooperative Bus Priority at Traffic Signals, IEEETransactions on IntelligentTransportation Systems, 13(1), pp.6-14., http://dx.doi.org/10.1109\%2fTITS.2011.2172869

International Energy Agency, (2009), World Energy Outlook, Paris, France: OECD/IEA.

International Energy Agency, (2009a), Transport, Energy and CO2: Moving Toward Sustainability, Annual Report, Paris, France: OECD/IEA.

Kadijk, G., Lingterink, N., van Mensch, P., Spreen, J., Vermeulen, R. and Vonk, W., (2015), Emissions of Nitrogen Oxides and Particulates of Diesel Vehicles, report No. TNO 2015 R10838, Delft, The Netherlands: TNO.

Molina, M., (2005), An Intelligent Assistant for Public Transport Management, Advances in Intelligent Computing, Lecture Notes in Computer Science, Heidelberg: Springer Berlin,Vol. 3645, pp. 199 - 208. http://dx.doi.org/ 10.1007/11538356_21

Nash, B., A. and Sylvia, R., (2001), Implementation of Zurich's Transit Priority Program, Mineta Transportation Institute Report 01-13, San Jose, CA, USA: San Jose State University.
PTV AG, (2014), PTV VISSIM 6 User Manual, Karlsruhe, Germany: PTV.

Scora G. and Barth, M., (2006), Comprehensive Modal Emission Model (CMEM), Version 3.01 User's Guide, Riverside: University of California.

Shamshirband S.: A Distributed Approach for Coordination Between Traffic Lights Based on Game Theory, The International Arab Journal of Information Technology, 2012; 9 (2), pp. 148-153.

Stathopoulos, F.G. and Noland R.B., (2003), Induced Travel and Emissions from Traffic Flow Improvement Projects, Transportation Research Record: Journal of the Transportation Research Board, 1842, pp. 57-63. http://dx.doi.org/10.3141/1842-07

Vujic, M., (2013), Dynamic Priority Systems for Public Transport in Urban Automatic Traffic Control, PhD, Zagreb: University of Zagreb, Faculty of Transport and Traffic Sciences.

Vujic,M.,Mandzuka,S.andGreguric,M.,(2015),PilotImplementation ofPublicTransport Priority in the City of Zagreb, Promet - Traffic \& Transportation, 27(3), pp. 257-265. http://dx.doi.org/10.7307/ptt.v27i3.1735

Zhizhou,W.,LiZ.andJianS.,(2014),AStudy ofDynamicRight-TurnSignalControlStrategy atMixedTrafficFlowIntersections,Promet-Traffic\&Transportation,24(6),pp.449-458., http://dx.doi.org/10.7307/ptt.v26i6.1357 